\title{
Endoscopic ultrasound-guided choledochoduodenostomy using partially-covered self-expandable metal stent in patients with malignant distal biliary obstruction and unsuccessful ERCP
}

\section{(ㅇ)( $\odot \Theta$}

\author{
Authors \\ Praveer Rai, CR Lokesh, Amit Goel, Rakesh Aggarwal
}

Institution

Department of Gastroenterology, Sanjay Gandhi

Postgraduate Institute of Medical Sciences, Lucknow, India

submitted 8.6.2017

accepted after revision 31.8.2017

Bibliography

DOI https://doi.org/10.1055/s-0043-120664 |

Endoscopy International Open 2018; 06: E67-E72

(c) Georg Thieme Verlag KG Stuttgart · New York

ISSN 2364-3722

Corresponding author

Dr Praveer Rai, Additional Professor, Department of

Gastroenterology, Sanjay Gandhi Postgraduate Institute of

Medical Sciences, Lucknow 226014, India

praveer_rai@yahoo.com

\section{ABSTRACT}

Background and study aims Endoscopic ultrasoundguided choledochoduodenostomy (EUS-CDS) is an alternative to percutaneous transhepatic biliary drainage (PTBD) for patients with malignant distal biliary obstruction in whom ERCP has failed. We studied technical success, clinical success, stent patency rate and occurrence of adverse events in patients undergoing EUS-CDS with partially-covered self-expanding metal stent (PCSEMS).

Patients and methods Medical records of consecutive patients with unresectable malignant distal biliary obstruction requiring biliary drainage who underwent EUS-CDS because of failure of attempt at ERCP were reviewed. EUS-CDS was done using 6-cm, PCSEMS (Wallflex, Boston Scientific). Technical success, clinical success (more than $50 \%$ reduction in total bilirubin at 2 weeks post-procedure), stent patency rate and adverse events (AEs) were assessed. Patients were followed up for 3 months post-procedure.

Results Between January 2015 and December 2016, 30 patients underwent EUS-CDS, including 20 (67\%) with failed biliary cannulation and $10(33 \%)$ with duodenal stenosis. Technical success was achieved in 28 patients, all of whom also had clinical success. Median total serum bilirubin decreased from $20 \mathrm{mg} / \mathrm{dL}$ to $5 \mathrm{mg} / \mathrm{dL}$ at 2 weeks postprocedure. Three patients (10\%) had adverse events (bile leak, hemobilia, stent block in one patient each; no stent migration); none of these adverse events was major and all were managed successfully. There were no procedure-related deaths. Five patients died of disease progression in the 3 -month period post-procedure, and the 3-month dysfunction-free stent patency rate was $83 \%$.

Conclusion EUS-CDS with a PCSEMS has a high technical and clinical success. Adverse events were infrequent, minor and could be managed easily.

\section{Introduction}

In patients with an obstructed biliary tree, biliary drainage is most often done using endoscopic retrograde cholangiopancreatography (ERCP). With an experienced endoscopist, the success rate for ERCP-guided drainage is above $95 \%$, and adverse events are infrequent, occurring in only around $5 \%$ to $10 \%$ of patients [1]. However, biliary cannulation is difficult in $15 \%$ to $22 \%$ of patients; in addition, it is not possible in $7 \%$ to $13 \%$ of patients with cancer of the pancreatic head, because concomitant duodenal stenosis precludes access of the endoscope tip to the major duodenal papilla [2,3]. In such patients, biliary drainage was previously done using percutaneous trans- hepatic biliary drainage (PTBD). However, in recent years, endoscopic ultrasound (EUS)-guided biliary drainage is emerging as an alternative method.

Of the various EUS-guided biliary drainage procedures (EUSBD), EUS-guided choledochoduodenostomy (EUS-CDS) and EUS-guided hepaticogastrostomy (EUS-HGS) are the most common [4]. In various case series, these procedures have been associated with technical and clinical success rates exceeding $90 \%$, and adverse event rates of $8 \%$ to $25 \%[5,6]$.

EUS-BD with fully-covered self-expandable metal stents (FCSEMSs) provides prolonged stent patency and decreases the risk of bile leak compared with EUS-BD with plastic stents $[7,8]$. However, FCSEMSs are associated with stent migration, 
and stent migration rates of $6 \%$ to $30 \%$ have been reported [ 9 11].

To decrease the risk of migration, lumen-apposing biflanged FCSEMS have been used for EUS-CDS. However, the biflanged shape and the large diameter of the delivery system for these stents pose a limitation in drainage of tubular bile ducts [12, 13]. Moreover, due to the relatively stiff delivery system for these stents, stent-related complications such as perforation, cholangitis, and stent migration have been encountered [14, 15].

Partially-covered self-expandable metal stents (PCSEMS) are also associated with a lower risk of stent migration, while providing the advantage of relatively small delivery system (diameter $=7.5 \mathrm{~F}$ ). . However, there are only a few reports of the use of PCSEMS for EUS-CDS. We therefore decided to assess the rates of technical and clinical success, and the frequency of adverse events associated with EUS-CDS using PCSEMS.

\section{Patients and methods}

\section{Patients}

We reviewed medical records of adult patients with unresectable malignant distal biliary obstruction, who required biliary drainage but in whom ERCP had failed (either because of duodenal stenosis or because of inability to cannulate major duodenal papilla) necessitating EUS-CDS between January 2015 and December 2016 at our tertiary-referral center. Failed cannulation and duodenal stenosis were defined as per the previously published criteria $[16,17]$. Patients with moderate-tolarge ascites, poor performance status (Karnofsky performance status $<70$ ), type 1 duodenal stenosis (obstruction of the second part of duodenum with involvement of the ampulla of Vater), surgical alteration of antroduodenal anatomy, prolonged prothrombin time (international normalized ratio $>1.5$ ), or low platelet count $(<50,000 / \mu \mathrm{L})$ were considered unsuitable for EUS-CD [18]. Complete blood counts, liver function tests, kidney function tests, prothrombin time were measured prior to the procedure.

\section{EUS-guided choledochoduodenostomy (EUS-CDS)}

All EUS-CDS procedures were performed by 1 endoscopist (PR), who had done 10 EUS-CDS procedures prior to the period of this study. All the procedures were done under propofol sedation, and after administration of a prophylactic dose of ceftriaxone (1 g intravenously). A linear echoendoscope (GF UCT 180; Olympus Ltd, Tokyo, Japan) was positioned in the first part of duodenum and the common bile duct was imaged. A transduodenal puncture of the bile duct was done using a 19-gauge EUSFNA needle (Expect ${ }^{\mathrm{TM}}$; Boston Scientific Corp., USA), while taking care to avoid any intervening blood vessels, which were identified using the color Doppler. To confirm the location of the needle tip, an aspiration was done; if bile was aspirated, then a cholangiogram was done to delineate the biliary anatomy. A guidewire was then passed into the biliary tree, and the tract between the gastrointestinal lumen and the biliary tree was dilated using a 6F cystotome (Endo-flex; Voerde, Germany). A $6-\mathrm{cm}$ partially-covered self-expandable metal stent
(PCSEMS) (Wallflex; Boston Scientific) was then placed over the guidewire under fluoroscopic and endoscopic guidance [4, $19,20]$. Patients in whom EUS-CDS failed underwent PTBD on the same day. $\mathbf{F i g .} 1$ illustrates the steps in EUS-CDS.

\section{Follow up}

All patients were followed up on outpatient basis at weeks 2, 4, and 12 , and in between if required. At each follow-up, a clinical evaluation was done, serum total bilirubin level was measured and any adverse events were recorded. Abdominal ultrasonography was done two days after the procedure for assessing the diameter of the common bile duct and the intrahepatic bile ducts, and at other visits if deemed necessary.

\section{Outcome measures}

The procedure was considered to be technically successful if the SEMS was correctly deployed at the intended position, as determined at fluoroscopy as well as endoscopy. Clinical success was defined as greater than $50 \%$ reduction in the total serum bilirubin level from baseline at 2 weeks post-procedure.

Any adverse events, such as occurrence of hemorrhage, perforation, major bile leak, stent migration, stent block, cholangitis, death or another untoward occurrence which could be attributed to the procedure, were recorded. Adverse events were defined and graded as per the guidelines of the American Society of Gastrointestinal Endoscopy [21].

\section{Ethics considerations and data analysis}

Continuous data were summarized as median and range and categorical data as proportions. All analyses were done on intention-to-treat basis. Our institution's Ethics Committee approved the study and each patient provided a written informed consent.

\section{Results}

\section{Patient characteristics}

Thirty patients ( $\triangleright$ Table 1 ) underwent EUS-CD. Among them, 15 had periampullary carcinoma, 6 had gallbladder carcinoma, 6 had carcinoma of the head of the pancreas and 3 had distal cholangiocarcinoma. In 20 patients, prior attempts at biliary cannulation had been unsuccessful and the remaining 10 patients had type 2 duodenal stenosis precluding access to the major duodenal papilla.

\section{Success rates}

- Table 2 shows the outcomes in our patients after EUS-CDS. EUS-CDS was technically successful in all patients except two. In one patient, though the initial bile duct puncture and placement of guidewire were successful, access of the biliary tree was lost subsequently. In another patient, the needle tract could not be dilated using the cystotome. Both the patients underwent PTBD on the same day. These failures occurred in our third and fifth patients, respectively. All 28 patients in whom EUS-CDS was performed successfully also achieved clinical success. Median serum bilirubin levels in the patients studied declined from $20 \mathrm{mg} / \mathrm{dL}$ to $5 \mathrm{mg} / \mathrm{dL}$ at 2 weeks post-procedure. 

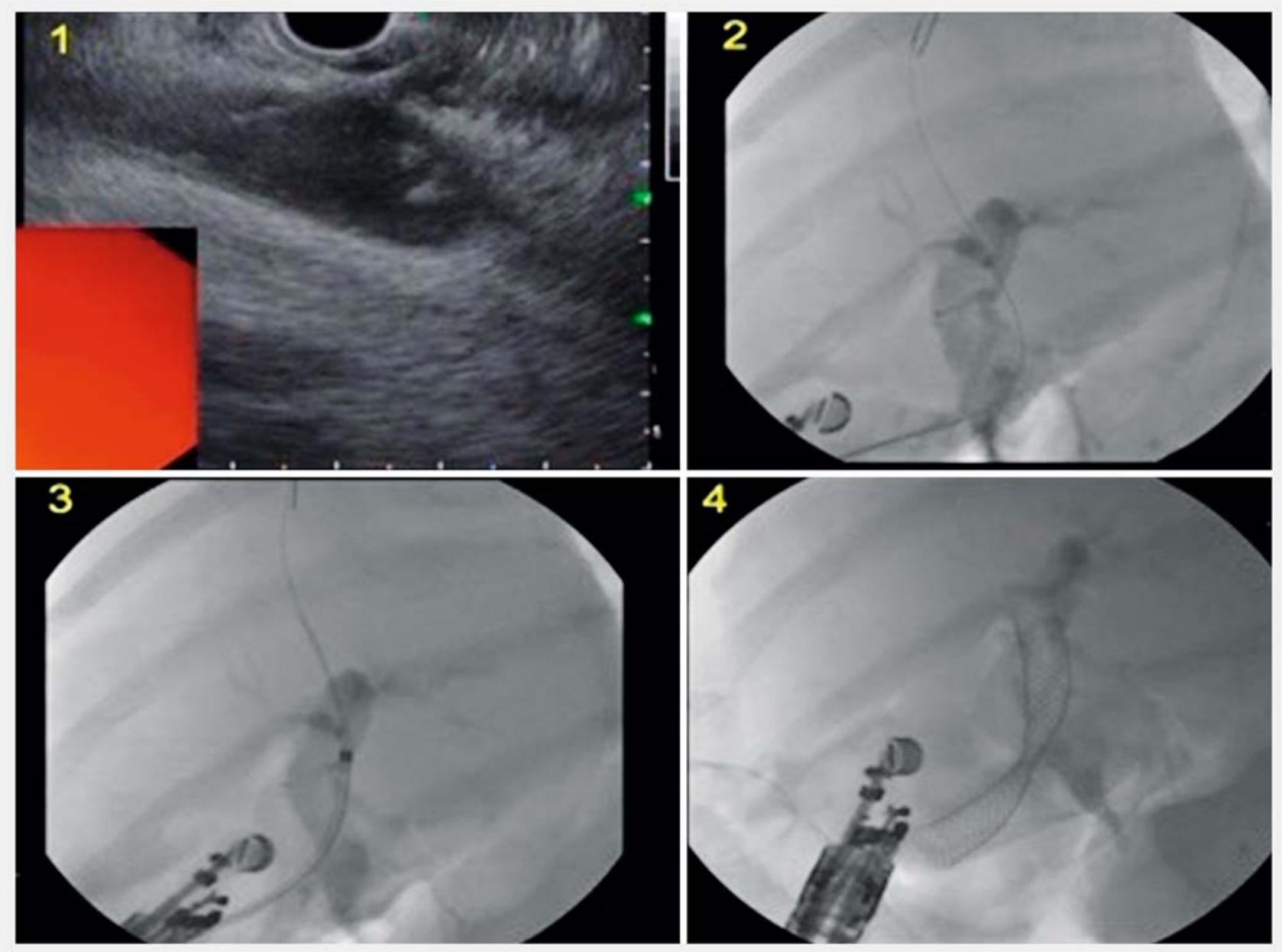

- Fig. 1 Steps in endoscopic ultrasound-guided choledochoduodenostomy.

- Table 1 Baseline characteristics of study patients $(n=30)$.

\begin{tabular}{|l|l|}
\hline Characteristic & Value \\
\hline Age in years, median (range) & $60.5(34-80)$ \\
\hline Male, $n(\%)$ & $16(53.3 \%)$ \\
\hline Cause of biliary obstruction, $n(\%)$ & \\
\hline - Periampullary carcinoma & $15(50 \%)$ \\
\hline - Gallbladder carcinoma & $6(20 \%)$ \\
\hline - Carcinoma head of pancreas & $6(20 \%)$ \\
\hline - Distal cholangiocarcinoma & $3(10 \%)$ \\
\hline Reason for failed ERCP, $n$ (\%) & $20(67 \%)$ \\
\hline - Failed cannulation & $10(33 \%)$ \\
\hline - Duodenal stenosis & \\
\hline ERCP, endoscopy regrade cholangiopancreatography & \\
\hline
\end{tabular}

\section{Adverse events}

Three patients had adverse events related to the procedure. One patient had a bile leak requiring a therapeutic paracentesis. One patient had bleeding at the duodenal puncture site which stopped spontaneously; this patient received 2 units of blood transfusion. In another patient, the stent got blocked with sludge; this was managed using endonasal biliary drain placement through the metal stent. None of the patients had cholangitis or stent migration. There were no procedure-related deaths.

\section{Follow-up}

During follow-up, 4 patients died due to progression of the underlying malignant disease (at $40-88$ days post-procedure). In 25 (83\%) of the 30 patients, the stent was patent and functioning normally at 3 months post-procedure.

\section{Discussion}

In our study, technical as well as clinical success with EUS-CDS was achieved in 28 of 30 (93\%) patients each. The only 2 failures occurred in our initial patients (third and fifth patients, 
- Table 2 Outcomes of endosonography-guided choledochoduodenostomy in study patients $(n=30)$.

\begin{tabular}{|l|c|}
\hline Parameter & Value \\
\hline Technical success, $\mathrm{n}(\%)$ & $28(93 \%)$ \\
\hline Clinical success, $\mathrm{n}(\%)$ & $28(93 \%)$ \\
\hline Total bilirubin in mg/dL, median (range) & \\
\hline - Baseline & $20(6-35)$ \\
\hline - 2 -week post-procedure & $5(2-18)$ \\
\hline Adverse events, n (\%) & \\
\hline - Bile leak (requiring therapeutic paracentesis) & $1(3 \%)$ \\
\hline - Bleeding & $1(3 \%)$ \\
\hline - Stent block & $1(3 \%)$ \\
\hline - Stent migration & 0 \\
\hline - Cholangitis & 0 \\
\hline - Death & 0 \\
\hline Procedure time, minutes & $30(24-45)$ \\
\hline Hospital stay, days & $4(3-22)$ \\
\hline 3-month dysfunction-free stent patency & $25(83 \%)$ \\
\hline Data are shown as median (range), or number (\%) & \\
\hline
\end{tabular}

respectively) and these were not observed in any of the subsequent patients. Only 3 (10\%) patients had adverse events, and all these adverse events were managed easily and there was no procedure-related death. During the 3-month follow-up period, none of the patients had stent migration. Our experience compares well with the results previously reported with EUSCDS.

Since its introduction, several reports on the use of EUS-CDS have been published. Most of these studies ( $\triangleright$ Table 3 ) have been retrospective case-series, with a few prospective series and randomized controlled studies $[9,15,22-26]$. The technical success rates in these studies have varied from $87 \%$ to $98 \%$, and the clinical success rates have been similarly high. In these series, adverse events have been observed in between $7 \%$ to $23 \%$ of patients, the most common of these being bleeding, bile leak, pneumoperitoneum, stent migration, cholangitis and abdominal pain. A systematic review and meta-analysis of 20 studies on EUS-BD [5], which included not only EUS-CDS, done in our study, but also EUS-HGS, EUS-rendezvous and EUS-guided antegrade stenting procedures, the cumulative success rate of these procedures was $90 \%$ and the cumulative adverse event rate was $17 \%$. Based on the above experience, EUS-guided approach to the biliary tree has become a frequently-used alternative to PTBD and surgical biliary drainage. Though PTBD has technical and clinical success rates similar to those of EUSCDS, it has a higher complication rate, making it inferior to

- Table 3 Comparison of our data with previous studies on EUS-guided choledochoduodenostomy.

\begin{tabular}{|c|c|c|c|c|c|c|c|}
\hline \multirow{2}{*}{$\begin{array}{l}\text { Author, year } \\
\text { [reference] }\end{array}$} & \multirow{2}{*}{$\begin{array}{l}\text { Study design } \\
\text { (number of } \\
\text { patients) }\end{array}$} & \multirow{2}{*}{$\begin{array}{l}\text { Type of stent } \\
\text { used (number } \\
\text { of patients) }\end{array}$} & \multicolumn{2}{|c|}{ Success rate } & \multicolumn{2}{|c|}{ Adverse events } & \multirow[b]{2}{*}{$\begin{array}{l}\text { Stent migra- } \\
\text { tion (number) }\end{array}$} \\
\hline & & & $\begin{array}{l}\text { Technical } \\
\text { (\%) }\end{array}$ & $\begin{array}{l}\text { Clinical } \\
(\%)\end{array}$ & $\begin{array}{l}\text { Number } \\
\text { (\%) }\end{array}$ & Nature & \\
\hline $\begin{array}{l}\text { Song et al., } \\
2012[9]\end{array}$ & $\begin{array}{l}\text { Retrospective } \\
(n=15)\end{array}$ & FCSEMS (15) & 87 & 100 & $\begin{array}{l}3 / 13 \\
(23 \%)\end{array}$ & $\begin{array}{l}\text { Peritonitis (2), cholangi- } \\
\text { tis (1) }\end{array}$ & 4 \\
\hline $\begin{array}{l}\text { Kawakubo et } \\
\text { al., 2014 [22] }\end{array}$ & $\begin{array}{l}\text { Retrospective } \\
(n=44)\end{array}$ & $\begin{array}{l}\text { FCSEMS (13) } \\
\text { PS (31) }\end{array}$ & 95 & NA & $\begin{array}{l}6 / 44 \\
(14 \%)\end{array}$ & $\begin{array}{l}\text { Bile leak (3), bleeding ( } 1 \text { ), } \\
\text { pneumoperitoneum ( } 1) \text {, } \\
\text { perforation (1) }\end{array}$ & 4 \\
\hline $\begin{array}{l}\text { Poincloux et } \\
\text { al. } 2015 \text { [23] }\end{array}$ & $\begin{array}{l}\text { Retrospective } \\
(n=30)^{1}\end{array}$ & $\begin{array}{l}\text { FCSEMS (26) } \\
\text { PS (3) }\end{array}$ & 97 & 93 & $\begin{array}{l}2 / 30 \\
(7 \%)\end{array}$ & Hemobilia (1), sepsis (1) & 0 \\
\hline $\begin{array}{l}\text { Artifon et al., } \\
2015 \text { [24] }\end{array}$ & $\begin{array}{l}\text { Randomized } \\
\text { controlled trial } \\
(n=24)\end{array}$ & PCSEMS (24) & 91 & 77 & $\begin{array}{l}3 / 24 \\
(13 \%)\end{array}$ & $\begin{array}{l}\text { Bile leak (1); bleeding ( } 1 \text { ); } \\
\text { perforation (1) }\end{array}$ & 0 \\
\hline $\begin{array}{l}\text { Dhir et al., } \\
2015 \text { [26] }\end{array}$ & $\begin{array}{l}\text { Retrospective } \\
(n=68)\end{array}$ & FCSEMS (68) & 97 & 93 & $\begin{array}{l}7 / 68 \\
(10 \%)\end{array}$ & $\begin{array}{l}\text { Bile leak (3); perforation (2); } \\
\text { cholangitis (1); stent migra- } \\
\text { tion (1) }\end{array}$ & 1 \\
\hline $\begin{array}{l}\text { Khashab et } \\
\text { al., 2016 [25] }\end{array}$ & $\begin{array}{l}\text { Prospective } \\
(\mathrm{n}=56)^{2}\end{array}$ & $\begin{array}{l}\operatorname{MS}(51)^{3} \\
\operatorname{PS}(5)\end{array}$ & NA & 96 & $\begin{array}{l}4 / 56 \\
(7 \%)\end{array}$ & $\begin{array}{l}\text { Bile leak (2), pneumoperito- } \\
\text { neum (1), bleeding ( } 1 \text { ) }\end{array}$ & 1 \\
\hline $\begin{array}{l}\text { Kunda et al., } \\
2016[15]\end{array}$ & $\begin{array}{l}\text { Retrospective } \\
(n=57)\end{array}$ & LA-FCSEMS (57) & 98 & 95 & $\begin{array}{l}4 / 57 \\
(7 \%)\end{array}$ & $\begin{array}{l}\text { Duodenal perforations (2), } \\
\text { bleeding (1), cholangitis (1) }\end{array}$ & 1 \\
\hline $\begin{array}{l}\text { Current } \\
\text { study, } 2017\end{array}$ & $\begin{array}{l}\text { Retrospective } \\
(n=30)\end{array}$ & PCSEMS (30) & 93 & 93 & $\begin{array}{l}3 / 30 \\
(10 \%)\end{array}$ & $\begin{array}{l}\text { Bile leak (1), bleeding (1), } \\
\text { stent block (1) }\end{array}$ & 0 \\
\hline \multicolumn{8}{|c|}{$\begin{array}{l}\text { FCSEMS, fully-covered self-expanding metal stent; PS, plastic stent; PCSEMS, } \\
\text { covered self-expanding metal stent } \\
126 \text { choledochoduodenostomy, } 1 \text { choledochojejunostomy, } 1 \text { choledochoant } \\
2 \text { Extrahepatic approach: CDS ( } 50 \text { ), hepaticoduodenostomy (4), rendezvous }\end{array}$} \\
\hline
\end{tabular}


EUS-BD [27]. Similarly, surgical biliary drainage is also associated with a much higher morbidity and mortality rate, and hence is currently not a preferred modality.

Our technical and clinical success rates with EUS-CDS were similar to those reported by others, and the complication rate was somewhat lower. Further, we found that our patients with EUS-CDS had an average hospital stay of only 4 days, much shorter than that required for PTBD. Thus, in our experience too, EUS-CDS, was a useful option in patients who have an otherwise untreatable advanced malignancy and needed biliary drainage for palliation.

We encountered 2 failures, both of which were among our initial 5 patients, with no failures thereafter. This observation points to the existence of an initial learning curve with these procedures, and emphasizes the importance of adequate training and experience, for an endosonologist to attain high technical and clinical success rates with a low risk of complications.

The nature of the stent used for EUS-BD may also be an important determinant of the success rate, and long-term results. Most previous studies on EUS-CDS have used FCSEMS, although some patients also received plastic or lumen-apposing stents ( $\triangleright$ Table 3). PCSEMS, however, have not been much used for EUS-CDS, having been used only in few studies [24]. We noticed that, in the available literature on EUS-BD, stent migration was a frequent complication. Hence, we decided to use PCSEMS, with the belief that the uncovered part at the 2 ends may help reduce the risk of migration, as has been shown previously [24]. This seems to have worked well since none of our patients had stent migration. We thus believe that the use of PCSEMS for EUS-BD in general, and for EUS-CDS in particular, needs to be explored further in larger studies.

Another feature of the published literature on these evolving procedures is that the technique has varied across various series and at times even between patients included in the same series. A particular problem with EUS-BD procedures is the non-availability of endoscopic accessories specifically designed for these [28]. Thus, the choice of accessories is often left to the endoscopists, who try to improvise using instruments available for other procedures. We used a 19-gauge EUS-FNA needle to puncture the tissue between the duodenal lumen and the bile duct, and a 6F cystotome to dilate the needle tract. These accessories are easily available and cheap, and worked well in our experience. Further, we tried to use a uniform technique across our patients, and used dilation which was just adequate for the deployment of PCSEMS; this may have been partly responsible for our high success rate and low rate of complications. We believe that it will be useful to compare the techniques used for EUS-CDS by the different endoscopists, and to determine their relative performances in attempt to harmonize these and develop an optimum technique.

Our study was limited by a retrospective design and a relatively short follow-up period, as has been true with many of the other reports too. As experience with EUS-BD techniques builds up, it would be important to undertake larger and prospective studies to further clarify their role in the management of malignant biliary obstruction.

\section{Conclusion}

In conclusion, we found that EUS-CDS with a partially-covered SEMS placement had high technical and clinical success rates, and a low rate of adverse events, which were generally minor. Thus, this procedure should be more widely applied in patients needing a biliary drainage procedure where the conventional ERCP-guided approach is not successful.

\section{Competing interests}

None

\section{References}

[1] Das A, Sivak MV Jr. Endoscopic palliation for inoperable pancreatic cancer. Cancer Control 2000; 7: 452-457

[2] Halttunen J, Meisner S, Aabakken L et al. Difficult cannulation as defined by a prospective study of the Scandinavian Association for Digestive Endoscopy (SADE) in 907 ERCPs. Scand J Gastroenterol 2014; 49: $752-758$

[3] Tuca A, Guell E, Martinez-losada E et al. Malignant bowel obstruction in advanced cancer patients: epidemiology, management, and factors influencing spontaneous resolution. Cancer Manag Res 2012; 4 : $159-169$

[4] Khashab MA, Levy M], Itoi T et al. EUS-guided biliary drainage. Gastrointest Endosc 2015; 82: 993-1001

[5] Khan MA, Akbar A, Baron TH et al. Endoscopic ultrasound-guided biliary drainage: A systematic review and meta-analysis. Dig Dis Sci 2016; 61: $684-703$

[6] Wang K, Zhu J, Xing L et al. Assessment of efficacy and safety of EUSguided biliary drainage: a systematic review. Gastrointest Endosc 2016; 83: $1218-1227$

[7] Park do H, Koo JE, Oh J et al. EUS-guided biliary drainage with onestep placement of a fully covered metal stent for malignant biliary obstruction: a prospective feasibility study. Am J Gastroenterol 2009; 104: $2168-2174$

[8] Park do H, Song T], Eum J et al. EUS-guided hepaticogastrostomy with a fully covered metal stent as the biliary diversion technique for an occluded biliary metal stent after a failed ERCP (with videos). Gastrointest Endosc 2010; 71: 413-419

[9] Song T], Hyun YS, Lee SS et al. Endoscopic ultrasound-guided choledochoduodenostomies with fully covered self-expandable metallic stents. World J Gastroenterol 2012; 18: 4435 - 4440

[10] Park do H, Jeong SU, Lee BU et al. Prospective evaluation of a treatment algorithm with enhanced guidewire manipulation protocol for EUS-guided biliary drainage after failed ERCP (with video). Gastrointest Endosc 2013; 78: $91-101$

[11] Ogura T, Kurisu Y, Masuda D et al. Novel method of endoscopic ultrasound-guided hepaticogastrostomy to prevent stent dysfunction. J Gastroenterol Hepatol 2014; 29: 1815-1821

[12] Glessing BR, Mallery S, Freeman ML et al. EUS-guided choledochoduodenostomy with a lumen-apposing metal stent before duodenal stent placement for malignant biliary and duodenal obstruction. Gastrointest Endosc 2015; 81: 1019-1020

[13] Itoi T, Binmoeller KF. EUS-guided choledochoduodenostomy by using a biflanged lumen-apposing metal stent. Gastrointest Endosc 2014; 79: 715 
[14] Bruckner S, Arlt A, Hampe J. Endoscopic ultrasound-guided biliary drainage using a lumen-apposing self-expanding metal stent: a case series. Endoscopy 2015; 47: 858-861

[15] Kunda R, Perez-Miranda M, Will U et al. EUS-guided choledochoduodenostomy for malignant distal biliary obstruction using a lumen-apposing fully covered metal stent after failed ERCP. Surg Endosc 2016; 30: $5002-5008$

[16] Testoni PA, Mariani A, Aabakken L et al. Papillary cannulation and sphincterotomy techniques at ERCP: European Society of Gastrointestinal Endoscopy (ESGE) Clinical Guideline. Endoscopy 2016; 48: $657-683$

[17] Mutignani M, Tringali A, Shah SG et al. Combined endoscopic stent insertion in malignant biliary and duodenal obstruction. Endoscopy 2007; 39: $440-447$

[18] Schag CC, Heinrich RL, Ganz PA. Karnofsky performance status revisited: reliability, validity, and guidelines. J Clin Oncol 1984; 2: 187 193

[19] Artifon EL, Ferreira FC, Otoch JP et al. EUS-guided biliary drainage: a review article. JOP 2012; 13: 7-17

[20] Ogura T, Higuchi K. Technical tips of endoscopic ultrasound-guided choledochoduodenostomy. World J Gastroenterol 2015; 21: 820828

[21] Cotton PB, Eisen GM, Aabakken L et al. A lexicon for endoscopic adverse events: report of an ASGE workshop. Gastrointest Endosc 2010; 71: $446-454$
[22] Kawakubo K, Isayama $\mathrm{H}$, Kato $\mathrm{H}$ et al. Multicenter retrospective study of endoscopic ultrasound-guided biliary drainage for malignant biliary obstruction in Japan. J Hepatobiliary Pancreat Sci. 2014; 21: 328 334

[23] Poincloux L, Rouquette O, Buc E et al. Endoscopic ultrasound-guided biliary drainage after failed ERCP: cumulative experience of 101 procedures at a single center. Endoscopy 2015; 47: 794-801

[24] Artifon EL, Marson FP, Gaidhane M et al. Hepaticogastrostomy or choledochoduodenostomy for distal malignant biliary obstruction after failed ERCP: is there any difference? Gastrointest Endosc 2015; 81: $950-959$

[25] Khashab MA, Schalk Van der Merwe S, Kunda R et al. Prospective international multicentre study on endoscopic ultrasound guided biliary drainage for patients with malignant distal biliary obstruction after failed endoscopic retrograde cholangiopancreatography. Endosc Int Open 2016; 4: E487-496

[26] Dhir V, Itoi T, Khashab MA et al. Multicenter comparative evaluation of endoscopic placement of expandable metal stents for malignant distal common bile duct obstruction by ERCP or EUS-guided approach. Gastrointest Endosc 2015; 81: 913 - 923

[27] Sharaiha RZ, Khan MA, Kamal F et al. Efficacy and safety of EUS-guided biliary drainage in comparison with percutaneous biliary drainage when ERCP fails: a systematic review and meta-analysis. Gastrointest Endosc 2017; 85: 904-914

[28] Fuccio L, Attili F, Vannela G et al. Interventional endoscopic ultrasonography. Curr Treat Options Gastroenterol 2014; 12: 183-210 